\title{
Consequências da Ruptura Ilícita do Contrato de Trabalho Desportivo na Lei Portuguesa - Uma Má Solução
}

\author{
Al bino Mendes Baptista \\ Mestre em Direito. Doutorando em Direito (Contrato \\ de Trabalho Desportivo). Assistente com Regência \\ de Direito do Trabalho na Faculdade de Direito da \\ Universidade Lusíada de Lisboa. Advogado. \\ mendes.baptista@sapo.pt
}

Sumário: Introdução. 1. Consequências da ruptura ilícita do contrato de trabalho desportivo. 2. Contrato de trabalho do praticante desportivo: contrato especial de trabalho. 3. Estabilidade e boa-fé contratual. 4. Deficiências legais. 5. Dignidade da pessoa humana e relação contratual. Conclusão. Referências.

Resumo: Procura-se apurar as consequências da ruptura ilícita do contrato de trabalho desportivo na lei portuguesa, concluindo-se que a limitação do dano a ressarcir às retribuições devidas até final do contrato constitui uma má solução legal. Julga-se mesmo que tal solução, além de insensata, desrazoável, desequilibrada e inconstitucional, pode constituir um acicate ao rompimento contratual, afecta gravemente o princípio da estabilidade contratual e não atende à especificidade do desporto.

Palavras-chave: Ruptura do contrato de trabalho desportivo. Reparação integral do dano. Estabilidade contratual.

\section{INTRODUÇÃO ${ }^{1}$}

Nos termos do n. ${ }^{\circ} 1$ do art. ${ }^{\circ} 2 .^{\circ}$ da Lei Portuguesa do Contrato de Trabalho Desportivo $^{2}$, nos casos de despedimento com justa causa promovido pela entidade

\footnotetext{
${ }^{1}$ O presente artigo corresponde, com alterações, ao nosso estudo em Baptista, n. . 4, 2009.

${ }^{2}$ Lei n. ${ }^{\circ}$ 28/98, de 26 de Junho. Doravante LCTD.
} 
empregadora desportiva e de rescisão com justa causa por iniciativa do praticante desportivo, a parte que der causa à cessação ou que a haja promovido indevidamente incorre em responsabilidade civil pelos danos causados em virtude do incumprimento do contrato, não podendo a indemnização exceder o valor das retribuições que ao praticante seriam devidas se o contrato de trabalho tivesse cessado no seu termo.

\section{CONSEQUÊNCIAS DARUPTURAILÍCITA DO CONTRATO DE TRABALHO DESPORTIVO}

As consequências para a ruptura ilícita do contrato de trabalho desportivo fixadas na lei portuguesa constituem, a meu ver, uma má solução legal.

Mas, como desde há muito venho defendendo, trata-se de uma solução insensata, desrazoável, desequilibrada e inconstitucional.

Sugerem-se os seguintes exercícios.

Pense-se na situação de um clube que disputa o título nacional, ou a presença em competições internacionais, ou mesmo a manutenção na respectiva divisão.

Faz sentido que num momento crucial da competição desportiva (por exemplo, a um ou dois meses do seu fim) um praticante abandone o clube a troco do pagamento das retribuições devidas até ao final do contrato que ocorre justamente nessa época desportiva?

Obviamente que não.

Suponhamos agora que um clube "ostraciza" um praticante desportivo uma época desportiva inteira, denigre a sua imagem e afecta a sua dignidade como pessoa. (Baptista, 2006, pp. 139 e ss.).

Os danos, desde logo não patrimoniais, provocados pela conduta do clube não podem gerar um direito a indemnização a favor do praticante desportivo?

Claro que podem.

Imagine-se ainda que um clube paga pela transferência de um praticante desportivo, por exemplo, € 20 milhões, e o contrato tem a duração de 3 anos. Se um jogador o romper ao fim de um ano da respectiva vigência, limitar-se-á a indemnizar o clube pelo valor das retribuições devidas até final do contrato?

É evidente que isso não faz sentido. Naturalmente que os custos de contratação têm de ter retorno para o clube.

Como escrevi no meu texto "Para uma leitura atenta e serena do 'Caso Webster" (Baptista, 2009):

Cada vez me surpreende mais a singularidade das nossas soluções jurídico-laborais desportivas que em certos casos me levam a pensar se foram feitas a pensar na sua aplicação a outra galáxia. 
Um dos exemplos mais expressivos de desadequação é o direito do praticante desportivo à reintegração no clube em caso de despedimento ilícito (art. ${ }^{\circ} 27 .^{\circ}$, n. $^{\circ}$ 2, da LCTD). Só quem não sabe minimamente o que é a realidade desportiva é que pode pensar que esta solução tem alguma razoabilidade.

A meu ver, o caminho correcto é o de estender a indemnização à totalidade dos prejuízos causados, reparando integralmente o dano.

\section{CONTRATO DE TRABALHO DO PRATICANTE DESPORTIVO: CONTRATO ESPECIAL DE TRABALHO}

Configurando-se o contrato de trabalho do praticante desportivo como um contrato de trabalho com regime especial, é inevitável que reflicta a especificidade da realidade desportiva (Baptista, 2008, pp. 191 e ss.).

E a consideração de que certo contrato tem regime especial impõe que se determine correctamente a respectiva especificidade, que se coloquem certas barreiras à aplicação das regras gerais que se mostrem desajustadas e que se atribua força expansiva a essa especificidade em sede de interpretação das respectivas normas.

Ora, o art. $^{\circ}$ 27. ${ }^{\circ}$, n. ${ }^{\circ}$ 1, da LCTD, como aliás quase todo o diploma, parece não atribuir qualquer importância às "circunstâncias de ordem desportiva", referidas expressamente, por exemplo, no ordenamento jurídico-laboral desportivo espanhol, como se as mesmas não tivessem relevância.

Julgo que era fundamental que a nossa lei permitisse a ponderação de factores como os que, a título naturalmente exemplificativo, se passam a enunciar:

- momento da competição desportiva escolhido para a ruptura contratual

- competição ou competições em que o clube está envolvido

- importância do praticante desportivo na equipa

- implicações no desempenho do colectivo

- consequências da desvinculação no grupo de trabalho

- lugar ocupado na equipa

- idade do praticante desportivo

- alternativas existentes no grupo do trabalho

- projecção do futuro do praticante desportivo

- custos de contratação

- afectação da imagem do clube

- frustração de contratos publicitários

- quebra de receitas desportivas. 
Um outro ponto que não pode ser desprezado nestas ponderações é a presença dos empresários desportivos na outorga dos contratos de trabalho, reforçando, e muito, o poder negocial dos praticantes, e afastando este tipo contratual do modelo clássico do contrato de trabalho comum.

Depois, não deve ser esquecida a sua intervenção em muitos processos de ruptura contratual dos praticantes. O empresário é, amiúde, o mais forte adversário do pacta sunt servanda, princípio de que gostam muito pouco, porque nada lhes adianta, enquanto que rupturas ante tempus, com a consequente outorga de novos contratos com clubes terceiros, geram circulação de dinheiro e, portanto, lucro para a sua actividade.

\section{ESTABILIDADE E BOA-FÉ CONTRATUAL}

Tais considerações obrigam, segundo se julga, a atentar na necessidade de dotar o ordenamento jurídico-desportivo de mecanismos que assegurem a estabilidade contratual e que protejam os clubes, sobretudo os pequenos, de autênticas tentativas de saque, tantas vezes consumadas.

Na verdade, a protecção das ligas menos ricas e dos pequenos clubes tem de passar a ser uma preocupação central dos legisladores e das organizações desportivas.

Importa também não olvidar que o praticante desportivo de alto nível domina a relação contratual.

Impõe-se ainda respeitar o investimento de confiança e observar o princípio da boa-fé.

Finalmente, é preciso reforçar o valor da palavra dada. Este é um problema que claramente extravasa o âmbito desportivo e que se prende com a construção de uma sociedade assente em princípios e valores.

É forçoso respeitar e cumprir pontualmente os contratos, princípio que os romanos expressaram na máxima de todos os tempos e de todas as latitudes pacta sunt servanda.

Atente-se no exemplo recente de Arséne Wenger, que recusou a tentadora oferta do Real Madrid, e que não invocou, nem deixou que invocassem por ele, qualquer qualidade de "escravo" e permaneceu fiel aos compromissos que livremente assumiu (Baptista, 2008, em www.apdd.pt.).

\section{DEFICIÊNCIAS LEGAIS}

As deficiências da lei e a inércia do legislador, que impõem a revisão urgente da LCTD, acabam de ser parcialmente "supridas" por duas decisões judiciais que sumariaremos. 
Em 1. ${ }^{\circ}$ lugar, merece destaque o Acórdão do Tribunal da Relação do Porto de 22 de Setembro de $2008^{3}$, por constituir a primeira decisão de um tribunal superior que vem concluir pela inconstitucionalidade do art. ${ }^{\circ} 27^{\circ}$, n. ${ }^{\circ}$ 1, da LCTD, por violação do princípio da igualdade, plasmado no art. ${ }^{\circ} 13 .{ }^{\circ}$ da Constituição da República Portuguesa ${ }^{4}$, ao estabelecer um limite "indemnizatório" máximo, em sede de ruptura ilícita do contrato de trabalho desportivo, quando, segundo aí se diz, todas as normas do Código do Trabalho relativas à cessação do contrato não limitam o dano a ressarcir (Baptista, n. ${ }^{\circ}$ 116, 2008, pp. 29 e ss.).

Esta decisão judicial foi confirmada pelo Acórdão do Tribunal Constitucional de 28 de Abril de 2009 (Proc. n. ${ }^{\circ}$ 910/08) .

O Tribunal Constitucional aceita que "os prejuízos efectivos da entidade empregadora podem atingir, no caso dos praticantes de maior destaque (cuja contratação implica, amiúde, um avultado investimento, como contrapartida da transferência do clube a que anteriormente estavam ligados) montantes significativamente mais elevados do que o limite legalmente fixado" e afirma-se que "o princípio da reparação integral dos danos é de direito comum - de que o contrato de trabalho desportivo está seguramente mais próximo do que o contrato laboral regido pelo Código do Trabalho"6.

E o Tribunal Constitucional conclui:

o art. ${ }^{\circ} 27 .^{\circ}$, n. ${ }^{\circ}$ 1, da LCTD, por confronto com o que se estabelece no Código do Trabalho, viola o princípio da igualdade, na medida em que prevê um limite máximo para a indemnização a arbitrar ao praticante desportivo que cesse o contrato antes do termo, com justa causa, limite esse que, no regime geral, corresponde ao mínimo indemnizatório a atribuir ao trabalhador do regime comum que cesse o contrato nas mesmas circunstâncias.

\section{DIGNI DADE DA PESSOA HUMANA E RELAÇÃO CONTRATUAL}

Pois bem, se é certo que o Tribunal Constitucional não apreciou a conformidade da referida norma no caso de ruptura ilícita do contrato por parte do praticante desportivo, a meu ver, é incontornável a afirmação da sua inconstitucionalidade também nesta situação, por violação, nomeadamente, do princípio da justa indemnização (Baptista, 2008, cit., pp. 29 e ss.).

\footnotetext{
${ }^{3}$ Publicado em www.dgsi.pt.

${ }^{4}$ Doravante CRP.

5 Publicado no Diário da República, 2. ${ }^{\text {a }}$ série, de 1 de Junho (de 2009).

${ }^{6}$ Sublinhado nosso.
} 
A República Portuguesa é um "Estado de direito democrático" (art. ${ }^{\circ}$ 2. ${ }^{\circ}$ da CRP) e baseia-se na "dignidade da pessoa humana" (art. ${ }^{\circ}$ 1. da CRP), disposições em que deve ser filiado o princípio da justa indemnização.

Em especial, refira-se que a reparação dos danos não patrimoniais constitui uma imposição do princípio do Estado de direito democrático.

Reparação de que naturalmente não podem ser excluídas as pessoas colectivas.

Como bem se decidiu no Acórdão do Supremo Tribunal de Justiça de 8 de Março de $2007^{7}$, as pessoas colectivas gozam também de direitos de personalidade relativos ao bom-nome, ao crédito e à consideração social.

\section{CONCLUSÃO}

Impressiona como é que, numa época em que se faz apelo crescente à defesa da pessoa e da sua dignidade, se persiste numa solução legal que não atribui sequer relevância, em sede de ruptura ilícita, aos danos não patrimoniais.

Pelas razões sumariamente expostas, o art..$^{\circ} 27^{\circ}$, n. $^{\circ}$ 1, da LCTD, assenta em pressupostos que estão em vias de extinção.

\section{REFERÊNCIAS}

BAPTISTA, Albino Mendes. "T hecompensation for theillicit breach of Sports $L$ abor $C$ ontract in the Portuguese L aw - an unw ise, unreasoning, unbal anced and unconstitutional sol ution", publicado em Sports L aw B ulletin, EPFL (European Professional Football Leagues), nº 4, 2009.

Estudos sobre o Contrato de Trabalho Desportivo. Coimbra: Coimbra Ed., 2006.

"Para uma leitura atenta eserena do "C aso W ebster": Publicado na Revista deDireito ede Estudos Sociais, Janeiro-Junho - 2009, Livraria Almedina, Coimbra, 2010.

Temas de Direito do Trabalho e de Direito Processual do Trabalho. Lisboa: Livraria Petrony, 2008.

"A "escravatura no futebol" ou a falta crescente de princípios e de respeito pelos adeptos?", disponível em : www.apdd.pt, acesso em: 18 jul. 2008.

" "Indemnização pela ruptura ilícita do contrato de trabalho, artigo 27.0 da L ei do Contrato de T rabalho D esportivo e 0 A córdão do T ribunal da R elação do Porto de 22 de Setembro de 2008", Revista do Ministério Público, no 116, 2008, pp. 29 e ss. 


\section{Referências jurisprudenciais}

Acórdão do Tribunal da Relação do Porto de 22 de Setembro de 2008, www.dgsi.pt.

Acórdão do Tribunal Constitucional de 28 de Abril de 2009 (Proc. n. ${ }^{\circ}$ 910/08), Diário

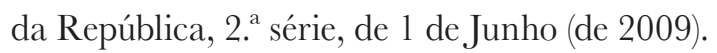

Acórdão do Supremo Tribunal de Justiça de 8 de Março de 2007, www.dgsi.pt.

\section{CONSEQUENCES OF THE ILLICIT BREACH OF SPORTS LABOR CONTRACT IN THE PORTUGUESE LAW - ABAD SOLUTION}

Abstract: Being the sporting labor contract one with a special regime, it is inevitable that it reflects the specificity of the sport. And, considering that the contract has a special regime, it is vital to determine accurately its respective specificity, to create some barriers to the general rules that are not adequate, and give more strength to that specificity when interpreting the respective provisions. It is astonishing how, in an era when the defense of the person and its dignity is so relevant, we keep insisting in a legal solution that does not give any importance to the general damages (including the psychological loss), in case of illicit breach. For all the reasons mentioned, it is concluded that the article 27, n. 1, of the LCTD, is based on assumptions that are becoming endangered.

Keywords: Sports Law. Portugal. Contract. 